with a large concave grating is to be used to obtain, if possible, spectra of the brighter stars. The expedition is under the immediate direction of Prof. Hale.

The ORBIT of COMET 1889 IV.-The following elements for comet 1889 IV. have been calculated by Dr. Guido Horn, of Trieste, and are published in No. 5, vol. xxxiii., of the Memorie della Societa degli Spettroscopisti Italiani:-

$$
\begin{aligned}
T & =1889 \text { July } 19 \cdot 32298 \text { (M.T. Berlin) } \\
\infty & =345^{\circ} 52^{\prime} 42^{\prime \prime} \cdot 83 \\
8 & =286^{\circ} 9^{\prime} \mathbf{1}^{\prime \prime} \cdot 31 \\
i & =65^{\circ} 59^{\prime} \mathbf{I ~ I ~}^{\prime \prime} \cdot 17 \\
\log q & =0.0169197 \\
\log e & =9^{\circ} 9990087 \\
\log a & =2 \cdot 6590039 \\
\text { Period } & =973^{\circ} \cdot 8 \mathrm{I} \text { years. }
\end{aligned}
$$

A table showing the similarity of the urbit of this comet to those of six others which have appeared since $x 684$ is also given.

New Lists of Variable Stars.-Circular No. 79 of the Harvard College Observatory contains a list of Ig new variable stars situated in the constellations Orion and Carina, and a list of 57 new. variables in the region of the small Magellanic Cloud. A careful examination of 1167 star images, contained in a region $3 \mathrm{o}^{\prime}$ square, on two plates of the Trifid nebula revealed no variables.

Circular No. 80 gives the positions and spectral characters of six new variables discovered by Mrs. Fleming on the Draper memorial photographs.

Circular No. $8 \mathrm{I}$ is devoted to some notes on eight variable stars of long periods prepared by Miss Cannon from her observations with the 6-inch telescope. The notes contain short comments upon the individual observations and on the agreement of the observed magnitudes on different dates with the various published elements for each star.

\section{THE EDUCATION OF THE AMERICAN} ENGINEER.

THE growing success of American and German manufacturers in the international competition for the world's markets has in recent years commanded alike the earnest attention of our industrial leaders and of our educational authorities. As numerous articles in these columns have testified, many serious attempts have been made during the past few years by expert observers from this country to try to discover the precise connection between foreign industrial success and the educational systems of the countries the competition of which has been brought home to us most decidedly; and the greatest attention has perhaps been given to the manner in which foreign engineers are prepared in schools and colleges for their life's work. It is little more than a year ago that Prof. W. E. Dalby laid before the Institution of Naval Architects and the Institution of Mechanical Engineers the results of his commission from $\mathrm{Mr}$. Yarrow to report on the training of engineers in other countries, and as recently as May 5 the report of the Mosely Educational Commission, which dealt at some length with the same subject, was reviewed in NATURE. The most recent contribution to this important subject is a paper by Dr. Mullineux Walmsley read before the Institution of Electrical Engineers, and published in the Journal of that society for May. Dr. Walmsley was given leave of absence by the governing body of the Northampton Institute, of which he is principal, and was instructed to investigate the methods of higher engineering education in the United States and Canada, and more particularly the effect, so far as it could be ascertained, of the education on the engineering industries, the views of the great manufacturers and employers on the value of the products turned out by the schools, and the attitude generally taken up by them towards these schools. The paper embodying the chief conclusions at which Dr. Walmsley arrived and the more important of his observations runs to fifty pages, and a few typical examples only can be given in the space available.

The paper is divided into six sections, the first five of which are concerned with higher mechanical and electrical engineering education to the practical exclusion of other branches of engineering instruction. It was originally No. I 8 IO, VOL. 70] intended to include a chapter on the training of bench hands, fitters and erectors; but eventually Dr. Walmsley contented himself with the statement that in many respects "our arrangements here for the training of bench hands, \&c., are better than the corresponding facilities provided in the United States and Canada."

The engineering schools and their resources are first described. The number and extent of the buildings devoted to higher engineering education exceeds, says the paper, anything that we can show in this country, but more often than otherwise Dr. Walmsley found that the supply of buildings was proving inadequate. There is: evidence throughout these American schouls of lavish expenditure on equipment on a scale to which we are, as yet, quite unaccustomed. The laboratories and workshops are packed full of apparatus and machinery for the use of students. The author states, "it is difficult within the limits of a paper not dealing exclusively with equipment to convey an adequate idea of its complexity or extent to those who have not visited the actual laboratories." The special needs of teachers and students engaged in research work receive particular attention by those who are responsible for the equipment of engineering workshops and laboratories, and the apparatus and fittings available include delicate instruments unlikely to be required by the ordinary student, but available for special investigations. It is interesting in this connection to quote an expression of opinion by Prof. Armstrong in the discussion on the paper :-.." Thete may be a good deal of provision made for research, but there is not much evidence of research work being done. What the colleges are suffering from very largely is great overprovision of appliances and under-provision of teachers and well-prepared students.'

Dr. Walmsley's remarks on the staffs of American engineering institutions agree with expressions of opinion to be found in the reports of Profs. Ayrton, Maclęan, and Ripper in the volume dealing with the Mosely Educational Commission. It may be said to be generally admitted in America that professors of engineering must be practical men possessing a modern working acquaintance with engineering processes on a commercial scale rather than men possessed of high academic qualifications. It is recognised by Transatlantic authorities, too, that it is all to the advantage of the students if the professor is also actively engaged in engineering practice, either as an advising expert or in some other capacity.

Financial considerations are given great prominence in the paper, and much the same ground is covered as that traversed by an article in NATURE of May 14, 1903, on "The University and the Modern State," though Dr. Walmsley, in addition, makes an interesting attempt to separate the expenditure on engineering from that on higher education as a whole. Many of the conclusions arrived at by Sir Norman Lockyer in his Southport address to the British Association are quoted and substantiated by the author's own observations.

A comparison is instituted between the mental stock-intrade with which American and English young men respectively start their engineering training, and though $\mathrm{Dr}$. Walmsley does not claim that the school training provided in the United States is perfect, he has little doubt of the greater suitability of the American training for boys intending to become engineers: "both because of the later age of entrance, and also because their general education, as a rule, has been carried to a higher point, it follows that the candidate for entrance into the technical courses in America is better equipped than those in this country to take advantage of the training of the professional school.:" Here, again, we find Prof. Armstrong dissenting; he is inclined to doubt altogether whether the average product which enters the colleges in America is in the least degree superior to the average product coming up to our colleges.

Under the heading "The Work of the Schools," much valuable material as to the characteristics of the engineering courses in the colleges of the United States is brought together. The rule is that in the first two years of the course - which generally lasts four years-a fair amount of time is given to mathematics, English, modern languages and experimental science, and it is chiefly in the workshop and drawing office that the specialisation towards engineering is apparent during these two years. Specialisation 
begins to show itself prominently early in the third year, and mechanical technology and electrotechnics are more or less taken up in the mechanical and electrical engineering courses. In the fourth year a crowd of engineering subjects is frequently introduced. An important part of the work of the fourth year is the preparation of a graduation thesis. The original intention, we find, of including such work in the time-table was undoubtedly to stimulate each student to produce, before he left the institution, a piece of original work which should be of some value in the development of science or of industry. In actual practice, however, the amount of original work produced is not very great, and it can be said fairly that only the best students do work which may be correctly dignified by the name of research. In most of the colleges post-graduate courses are organised, and in these the best work of the college is done.

But in no respect are American conditions more different from those at home than in the attitude of the employers of labour towards higher education. Just as the engineering experts on the Mosely Commission were unanimous in praising the interest shown by American manufacturers in the work of the colleges, so Dr. Walmsley testifies to the same fact. "Without exception the officials interviewed asserted that, far from having any difficulty in placing the graduates turned out year by year from the engineering courses, for the last few years the graduate class has had every one of its individual members engaged for remunerative work before the completion of the course at college." Later it is stated, " many of the large employers have made it a sine qua non for entrance to any position which may lead eventually to a place on the scientific staff, that the candidate should have passed satisfactorily through the full four years' course at an approved technical institution." More than this, no premium is demanded, and living wages are given from the beginning, and these are raised as soon as the young beginner shows himself to be worth more.

Dr. Walmsley concludes his valuable paper with a summary of the respects in which this country is behind the United States so far as the education of its engineers is concerned. He enumerates the following deficiencies:First, the comparative lack of support and encouragement of the work of the colleges by our leading manufacturers; secondly, that even were our employers ready to adopt the American plan of securing the services of students from the engineering schools, our present schools are neither equipped nor staffed to produce in sufficiently large numbers the trained men who would be wanted; and thirdly, that parents and guardians in this country have not yet been educated to understand how essential, in view of recent developments, a college training is to the success in the future of a candidate for the engineering profession.

As Mr. Buckmaster remarked during the course of the resumed discussion on Dr. Walmsley's paper, it " will be for a long time to come a sort of mine into which each of us will dig." This report together with the others to which reference has been made are more than sufficient to show educational authorities the direction in which our systems of instruction can be improved, and it is earnestly to be hoped that these and similar warnings will not have been uttered in vain.

A. T. S.

\section{ARCHAOLOGICAL INVESTIGATIONS IN RUSSIAN TURKESTAN.}

D R. D. C. GILMAN, president of the Carnegie Institution of Washington, has received a letter in which Prof. R. Pumpelly describes some interesting results of his investigations upon ancient sites, at Anau, near Aschabad, in Russian Turkestan. The following extract from this communication will be welcomed by all who are interested in prehistoric and archæological researches :-

We have explored more than 136 feet of successive culture strata, containing at least four almost uninterrupted culture stages, extending apparently for thousands of years through the Neolithic and Bronze into the beginning of the Iron stage, and we have correlated the stages of culture with important events in the physiographic history and with the introduction of irrigation.

The streams that rise in the high mountains of northern Persia emerge on to the Turkoman plains forming fans, or NO. I8IO, VOL. 70] subaërial deltas, covering many square miles, and each making an oasis. The water is all used in irrigating these fertile spots. Beyond them is the desert. Anau, where we have excavated, is on one of these fans.

Here at Anau, about seven miles east of Aschabad, there are two great tumuli, and the ruins of a city-Anausurrounded by moat and wall, and occupied until within the last century. The two tumuli, nearly half a mile apart, are nearly equidistant from the city at a distance of less than a mile. We have explored both of these tumuli, and I have done some work in the city.

The northern and older tumulus rises 40 feet above the plain; the southern and younger tumulus rises $5^{i}$ feet above the plain. Both of these start with their lowest culture strata on slight elevations in the same original plain-surface -more than 20 feet below the present surface of the surrounding plain. That is to say, the plain has grown up more than 20 feet since the settlements began. I will show, further on, the different phases of this growth.

In the older tumulus, we find a culture occupying the lower 45 feet, and distinguished by the technique and decoration of its wholly hand-made and interesting pottery. This is succeeded in the upper $I_{5}$ feet by a more advanced culture in which some remnants of bronze implements and lead beads (all wholly altered to salts of the metals) show a beginning acquaintance with bronze, while the still hand-made pottery has changed and become more developed.' Throughout this tumulus we have found nothing recognisable as a weapon of offence in either stone or metal, though flint knives abound.

The southern, younger tumulus, starts with a developed wheel-made pottery, unpainted, and of a technique wholly different from that of the older tumulus-though some handmade pottery occurs not wholly unlike some of the younger products of the older tumulus.

From its base under the plain to its summit this tumulus has 74 feet of culture strata. There are evident here at least two successive cultures. Of these, that of the lower 62 feet is wholly in the bronze stage (but with survival of flint implements), while the upper I4 feet are marked by decided changes and by the introduction of iron, of which the wholly oxidised remnants of some implements were found.

We have thus at least four distinct cultures occupying 136 feet, with a break in the column between the end of the old and the beginning of the new tumulus. We do not know how great this gap may be.

Through all the cultures except the last-that of the iron stage - there ran a remarkable and characteristic burial custom. The children-at least certain children-and seemingly only children, were buried in the houses, under the floor, on a layer of fire-hardened earth.

In addition to the work on the two tumuli, I have sunk four shafts to the culture strata ( 30 to 40 feet thick) of the city of Anau, to try to determine its age relative to that of the youngest culture of the tumuli, and to get facts for use in deciding as to when irrigation was introduced. The results prove that Anau was wholly in the iron stage, while its wheel-made pottery is wholly different from any in the tumuli; but, in addition to this, fine-glazed faience was found plentifully in the upper three-quarters of all three shafts. These were not found at all in the tumuli, excepting in the case of two or three isolated and very doubtful pieces.

The history of the whole series of culture strata is sharply characterised by the following four periods in the history of the plain or subaërial delta :-

(1) The north tumulus when founded stood on a hill at least 7 feet, and probably more, above the plain surface, it = culture spreading down the slopes. The plain was aggrading, and continued to grow until it had buried the base of the tumulus to a depth of 2 feet. By that time, or soon after, the north tumulus was abandoned, and the south tumulus culture founded, on an elevation about 2 feet above the plain. The plain continued to grow until it had buried the base of the south tumulus to a depth of 14 feet.

(2) Then followed a change of conditions. The plain was cut down at least ig feet.

(3) This was followed by another change which caused the refilling of the cutting to the amount of 8 feet, 7 feet of this last growth having occurred after the deposition in 